\title{
PERANCANGAN DAN IMPLEMENTASI AUGMENTED REALITY SEBAGAI MEDIA PROMOSI PENJUALAN PERUMAHAN
}

Alan ZuniargoPrabowo ${ }^{1)}$, Kodrat Iman Satoto ${ }^{2)}$, Kurniawan Teguh Martono ${ }^{2)}$ Program Studi Sistem Komputer, Fakultas Teknik, Universitas Diponegoro Jln. Prof. Sudharto, Tembalang, Semarang, Indonesia Email: alanzp@ymail.com

Untuk melakukan promosi sebuah perumahan banyak cara yang dapat dilakukan, misalnya dengan menggunakan brosur yang mana informasinya disampaikan dalam media dua dimensi, maket yang mana informasinya sudah dapat disampaikan dalam media tiga dimensi tetapi harus memerlukan ruang yang tidak sedikit untuk mewujudkannya demi mendapatkan hasil yang maksimal. Yang menjadi masalah disini adalah bagaimana menjadikan suatu informasi tersebut menjadi interaktif dan lebih menarik bagi konsumen.

Dengan menggunakan teknik promosi berbasis augmented reality yang dibuat dengan menggunakan ARTool Kit sebagai komponen yang utama dan dengan menggunakan 3DS Max sebagai software untuk menghasilkan gambar yang menarik. Proses perancangan dan pembuatan teknik promosiini akan menggunkan metode waterfall. Kelebihan dari model waterfall adalah struktur tahap pengembangan sistem jelas, dokumentasi dihasilkan disetiap tahap pengembangan, dan sebuah tahap dijalankan setelah tahap sebelumnya selesai dijalankan (tidak ada tumpang tindih pelaksanaan tahap).

Hasil dari perancangan aplikasi ini adalah terealisasinya suatu aplikasi untuk kepentingan promosipenjualan perumahan yang lebih menarik dan interaktif dengan konsumen berbasis augmented reality. Dengan adanya aplikasi ini diharapkan metode promosi dapat berkembang dengan lebih menarik dan tentunya dengan mengandalkan teknologitanpa membutuhkan ruang yang banyak untuk mencapai hasil yang maksimal.

Kata Kunci :Aplikasi Promosi, Augmented Reality, ARToolkit, Perumahan

\section{PENDAHULUAN}

\subsection{Latar Belakang}

Perkembangan teknologi semakin pesat pada saat ini. Kemajuan ini menjadikan teknologi komputer semakin mendominasi. Peran komputer pun sekarang sudah bergeser yang awalnya digunakan sebagai mesin hitung, sekarang sudah merambah ke barbagai aspek kehidupan, mulai dari hiburan, administrasi, dan bahkan dalam dunia bisnis. Dalam strategi pemasaran pun peran teknologi komputer semakin hari semakin meningkat. Banyak instansi yang memanfaatkan kemajuan teknologi untuk promosi.

Dalam bidang komputer terdapat teknologi yang disebut Augmented Reality atau yang biasa disingkat AR. Pada dasarnya AR memiliki kelebihan yaitu mampu memberikan pengalaman dan pemahaman yang mendalam bagi user. Ini berarti tidak menutup kemungkinan bahwa teknologi ini dapat dijadikan alat untuk metode promosi yang lebih menarik, semisal dengan menyorotkan kamera yang terhubung dengan computer ke katalog promosi perumahan, konsumen bisa melihat secara tiga dimensi bagaimana tampilan rumah yang terdapat dalam katalog promosi perumahan.

Dalam strategi promosi, khususnya promosi perumahan bisa saja dilakukan dengan berbagai media. Tetapi sekarang yang menjadi masalah banyaknya metode promosi yang mudah dibuat, tetapi hasilnya kurang maksimal. Metode lain dapat dilakukan dan dapat mencapai hasil yang lebih maksimal tetapi harus mengeluarkan biaya yang tidak sedikit dan memakan ruang yang tidak sedikit pula. Dengan menggunakan teknologi Augmented Reality metode yang hasilnya kurang maksimal, biaya yang besar, ruang yang tidak sedikit itu dapat diminimalisir, sehingga dapat menjadi metode promosi penjualan perumahan yang lebih menarik karena Augmented Reality mampu memberikan pengalaman dan pemahaman yang lebih mendalam bagi konsumen.

\subsection{Rumusan Masalah}

1. Bagaimana merancang media promosi berbasis Augmented Reality.

2. Bagaimana menjadikan suatu teknologi Augmented Reality agar bisa bermanfaat bukan hanya dalam bidang komputer tetapi dalam bidang lain yaitu strategi pemasaran / promosi.

3. Bagaimana menjadikan sebuah metode promosi penjualan perumahan berbasis teknologi Augmented Reality terlihat lebih nyata dan sekaligus menjadikan sebuah pengalaman baru bagi konsumen.

\subsection{Batasan Masalah}

Penulisan tugas akhir ini pembahasan masalah memiliki batasan dalam hal berikut:

1. Aplikasi ini berjalan pada sistem operasi Windows.

2. Aplikasi ini bekerja pada basis Augmented Reality dengan ARToolkit sebagai komponen pembuatnya.

3. Aplikasi ini berfungsi untuk menampilkan animasi model rumah bagian luar, dalam, dan satu cluster secara tiga dimensi dalam layar monitor.

4. Objek perumahan 3 dimensi dikembangkan menggunakan teknologi VRML (Virtual Reality Modeling Language) dengan menggunakan software Autodesk 3D Studio Max.

1.4 Tujuan 
1. Merancang aplikasi Augmented Reality sebagai media promosi perumahan.

2. Mengimplementasikan Augmented Reality sebagai media promosi penjualan perumahan.

3. Menjadikan teknologi Augmented Reality bermanfaat sebagai salah satu metode atau cara untuk mendapatkan pengalaman baru dalam strategi pemasaran.

\section{DASAR TEORI}

\subsection{Augmented Reality}

Augmented reality merupakan salah satu perkembanganteknologi yang digunakan pada akhirakhir ini di dibidang interaksi. Penggunaan teknologi ini akan sangat membantu dalam menyampaikan suatu informasi kepada pengguna dengan cara yang berbeda dan lebih menarik. Augmented Reality merupakan teknologi interaksi yang menggabungkan antara dunia nyata (real world) dan dunia maya (virtual world).

Tujuan dalam penggunaan teknologi Augmented Reality ini adalah menambahkan pengertian dan informasi pada dunia nyata dimana sistem Augmented Reality mengambil dunia nyata sebagai dasar dan menggabungkan beberapa teknologi dengan menambahkan data kontekstual agar pemahaman seseorang menjadi jelas.

Prinsipnya secara umum menurut Ronald $\mathrm{T}$. Azuma (1997:2) masih sama dengan virtual reality, yaitu bersifat interaktif, immersion (membenamkan/ memasukkan), realtime, dan objek virtual biasanya berbentuk 3 dimensi. Namun kebalikan dari virtual reality yang menggabungkan objek nyata (user) kedalam lingkungan virtual, augmented reality menggabungkan objek virtual pada lingkungan nyata. Kelebihan utama dari Augmented reality dibandingkan virtual reality adalah pengembangannya yang lebih mudah dan murah (Kauffman,2002:4).

\subsection{ARToolkit}

ARToolkit adalah software library untuk membangun Augmented Reality (AR). Aplikasi ini adalah aplikasi yang melibatkan overlay pencitraan virtual ke dunia nyata. Untuk melakukan ini, ARToolkit menggunakan pelacakan video, untuk menghitung posisi kamera yang nyata dan mengorientasikan pola pada kertas marker secara realtime. Setelah, posisi kamera yang asli telah diketahui, maka virtual camera dapat diposisikan pada titik yang sama, dan objek 3D akan digambarkan diatas marker. Jadi ARToolkit memecahkan masalah pada AR yaitu, sudut pandang pelacakan objek dan interaksi objek virtual.

ARToolkit menggunakan teknik visi komputer untuk mengkalkulasikan sudut pandang kamera nyata ke marker yang nyata. Ada lima langkah, dalam proses kerja ARTookit, Pertama kamera, mencari marker, kemudian marker yang dideteksi dirubah menjadi binary, kemudian black frame atau bingkai hitam akan terdeteksi oleh kamera. Langkah kedua adalah, kamera akan menemukan poisisi marker 3D dan dikalkulasikan dengan kamera nyata. Langkah ketiga, kamera akan mengindentifikasi marker, apakah pola marker sesuai dengan templates memory. Langkah ke empat, dengan mentrasformasikan posisi marker. Langkah kelima, objek 3D di render diatas marker.

\subsection{Autodesk 3D Studio Max}

3D studio max atau biasa dikenal dengan 3ds max merupakan salah satu software yang sangat populer di dunia animasi, karena mudah dipelajari dan praktis digunakan, dan juga tidak hanya untuk membuat animasi, 3ds Max juga dapat digunakan bagi desainer atau arsitek atau para pengembang game atau bagi siapa saja yang ingin mevisualisasikan karya-karya mereka, dan juga $3 \mathrm{ds}$ Max dapat berintegrasi dengan software-software lain seperti Unity, Blender, AutoCad, bahkan dengan software yang secara teknis memiliki fungsi yang sama digunakan dengan plug-in yang digunakan untuk software lain.

Fitur-fitur yang di sediakan di dalamnya memungkinkan user menuangkan semua ide kreatif ke dalam komputer. Dapat dikatakan, bahwa kemampuan 3ds Max dibatasi oleh imajinasi user, yaitu seberapa jauh user mampu mengelola dan mengoptimalkan semua fitur yang ada dalam 3ds Max. (Soma 2007)

\subsection{Microsoft Visual Studio}

Microsoft Visual Studio merupakan sebuah perangkat lunak lengkap (suite) yang dapat digunakan untuk melakukan pengembangan aplikasi, baik itu aplikasi bisnis, aplikasi personal, ataupun komponen aplikasinya, dalam bentuk aplikasi console, aplikasi Windows, ataupun aplikasi Web. Visual Studio mencakup kompiler, SDK, Integrated Development Environment (IDE), dan dokumentasi (umumnya berupa MSDN Library). Kompiler yang dimasukkan ke dalam paket Visual Studio antara lain Visual C++, Visual C\#, Visual Basic, Visual Basic .NET, Visual InterDev, Visual J++, Visual J\#, Visual FoxPro, dan Visual SourceSafe.

Microsoft Visual Studio dapat digunakan untuk mengembangkan aplikasi dalam native code (dalam bentuk bahasa mesin yang berjalan di atas Windows) ataupun managed code (dalam bentuk Microsoft Intermediate Language di atas .NET Framework). Selain itu, Visual Studio juga dapat digunakan untuk mengembangkan aplikasi Silverlight, aplikasi Windows Mobile (yang berjalan di atas .NET Compact Framework).

Visual Studio kini telah menginjak versi Visual Studio 9.0.21022.08, atau dikenal dengan sebutan Microsoft Visual Studio 2008 yang diluncurkan pada 19 November 2007, yang ditujukan untuk platform Microsoft .NET Framework 3.5. Versi sebelumnya, 
Visual Studio 2005 ditujukan untuk platform .NET Framework 2.0 dan 3.0. Visual Studio 2003 ditujukan untuk .NET Framework 1.1, dan Visual Studio 2002 ditujukan untuk .NET Framework 1.0. Versi-versi tersebut di atas kini dikenal dengan sebutan Visual Studio .NET, karena memang membutuhkan Microsoft .NET Framework. Sementara itu, sebelum muncul Visual Studio .NET, terdapat Microsoft Visual Studio 6.0 (VS1998). (Wahana Komputer 2008)

\subsection{Virtual Reality Modeling Language (VRML)}

VRML (Virtual Reality Modelling Language) adalah sebuah bahasa pemrograman yang diciptakan khusus untuk membuat objek-objek 3D. Objek-objek yang dibuat dengan VRML akan memiliki tiga buah dimensi panjang, lebar dan kedalaman, sehingga dapat dipandang dari setiap sudut (Kurniadi 1999). Bahasa ini memberikan berbagai kemudahan bagi pengguna untuk melakukan visualisasi objek-objek 3D (Anwar 1999b). VRML menggambarkan objek 3D yang dapat dikendalikan secara interaktif oleh pengguna dan dapat ditampilkan pada web (Anwar 1999a).

VRML menggunakan prinsip OOP (object Oriented Programming), sama seperti program generasi baru lainnya. Prinsip ini membagi setiap bagian di dalam program menjadi objek-objek yang terpisah-pisah.

\subsection{Unified Modeling Language(UML)}

Unified Modelling Language (UML) adalah sekumpulan pemodelan konvensi yang digunakan untuk menentukan atau menggambarkan sebuah sistem perangkat lunak dalam kaitannya dengan objek. (Whitten, 2004, p430).

UML dapat juga diartikan sebuah bahasa grafik standar yang digunakan untuk memodelkan perngkat lunak berbasis objek. UML pertama kali dikembangkan pada pertengahan tahun 1990an dengan kerjasama antara James Rumbaugh, Grady Booch, dan Ivar Jacobson yang masing-masing telah mengembangkan notasi mereka sendiri di awal tahun 1990an. (Lethbride dan Leganiere, 2002, p151).

Dengan menggunakan UML kita dapat membuat model untuk semua jenis aplikasi piranti lunak, dimana aplikasi tersebut dapat berjalan pada piranti keras, sistem operasi dan jaringan apapun, serta ditulis dalam bahasa pemrograman apapun Tetapi karena UML juga menggunakan class dan operation dalam konsep dasarnya, maka lebih cocok untuk penulisan piranti lunak dalam bahasa- bahasa berorientasi objek sepert $\mathrm{C}++$, Java, C\# atau VB.NET.Walaupun demikian,UML tetap dapat digunakan untuk modeling aplikasi prosedural dalam VB atau C. Seperti bahasa-bahasa lainnya, UML mendefinisikan notasi dan syntax. Notasi UML merupakan sekumpulan bentuk khusus untuk menggambarkan berbagai diagram piranti lunak.

\subsection{Metode Pengembangan Waterfall}

Model air terjun (waterfall) sering juga disebut model sekuensial linier atau alur hidup klasik (clasic life cycle). Model air terjun menyediakan pendekatan alur hidup perangkat lunak secara sekuensial atau terurut dimulai dari analisis, desain, pengodean, pengujian, dan tahap pendukung (support) (A.S. \& Shalahuddin 2013).

\section{PERANCANGAN SISTEM}

\subsection{Analisis Kebutuhan}

\subsubsection{Kebutuhan Fungsional}

Kebutuhan fungsional merupakan fungsionalitas atau layanan yang harus diberikan oleh sistem. Analisis kebutuhan fungsional pada aplikasi ini sangat diperlukan dalam mendukung kinerja aplikasi, apakah aplikasi yang dibuat sudah sesuai kebutuhan yang diperlukan oleh pengguna. Fungsi aplikasi yang dibuat ini adalah aplikasi mampu menampilkan objek virtual 3D perumahan di atas marker yang telah terdeteksi oleh webcam pada layar monitor.

\subsubsection{Kebutuhan Non Fungsional}

a. Operasional

Aplikasi ini dapat berjalan pada komputer dengan sistem operasi Windows.

b. Antarmuka / Interface

Aplikasi memerlukan perangkat keras untuk data masukan berupamouse dan webcam serta memerlukan layarmonitor untuk menampilkan keluaran.

\subsection{Analisis Sistem}

\subsubsection{Diagram Use Case}

Diagram use case merupakan pemodelan untuk menggambarkan kelakuan (behavior) sistem yang akan dibuat. Terdapat beberapa simbol dalam menggambarkan diagram use case yaitu aktor, use cases dan hubungannya. Aktor adalah entitas manusia, proses atau mesin yang berinteraksi dengan sistem, subsistem atau kelas.

Diagram use case dari perancangan aplikasi dapat dilihat pada gambar 1 . 


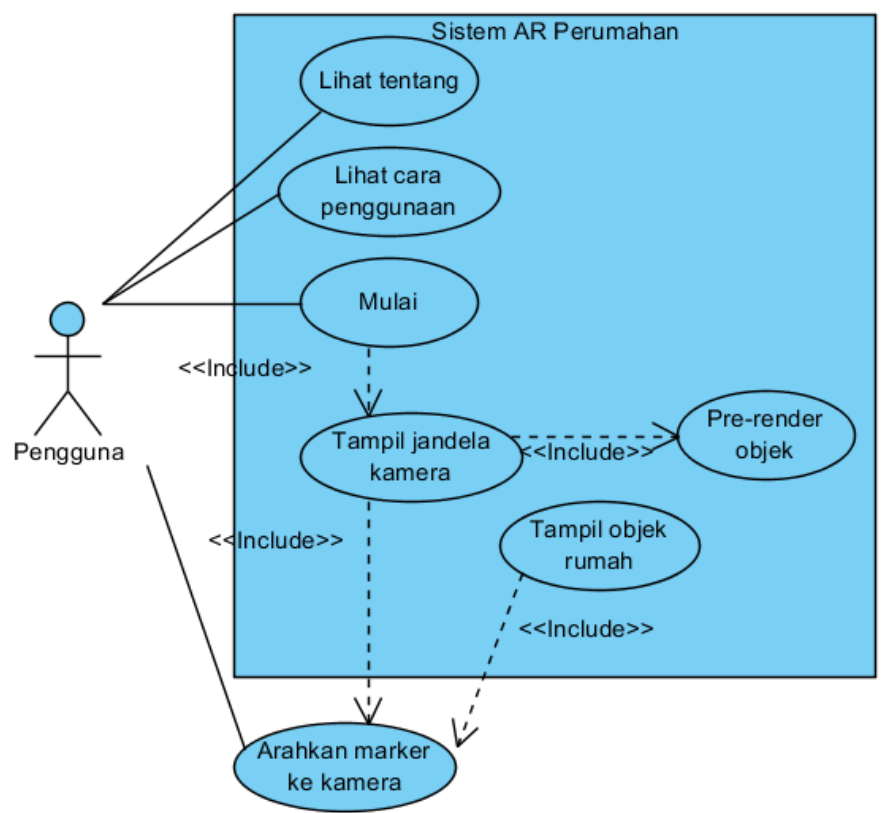

Gambar 1.Diagram use case perancangan aplikasi

\subsubsection{Sequence Diagram}

Diagram sekuen (sequence) menggambarkan kelakukan/perilaku objek pada use case dengan mendeskripsikan waktu hidup (lifeline) objek dan pesan (message) yang dikirimkan dan diterima antar objek. Diagram sekuen menujukkan objek sebagai garis vertikal dan tiap kejadian sebagai panah horizontal dari objek pengirim ke objek penerima.Diagram sekuen dari perancangan ini adalah sebagai berikut:

1. Diagram sekuen untuk use case mulai

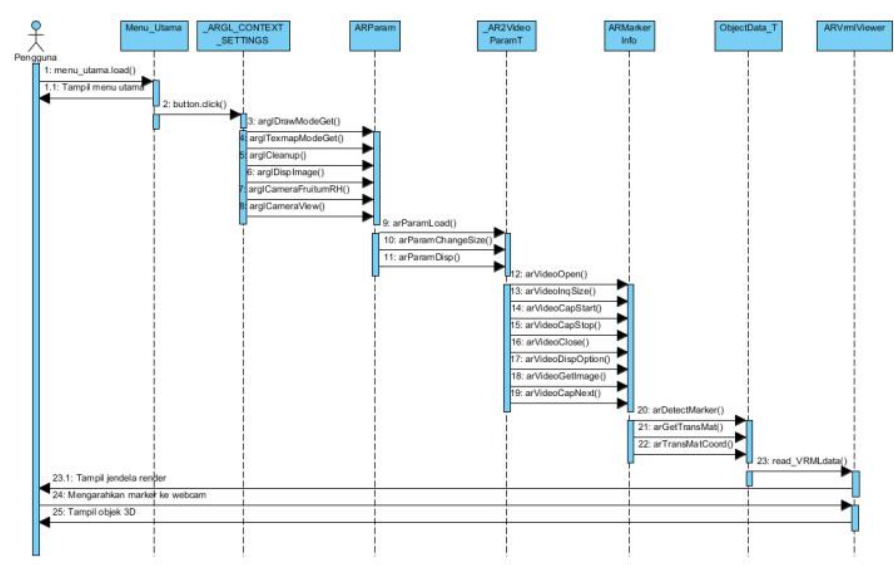

Gambar 2.Diagram sekuen mulai
2. Diagram sekuen untuk use case lihat cara penggunaan

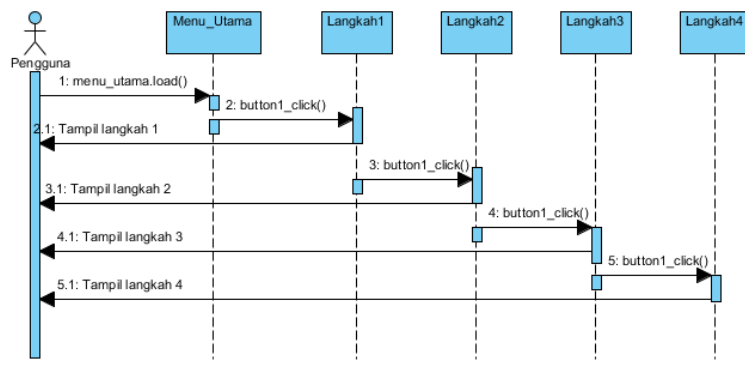

Gambar 3.Diagram sekuen lihat cara penggunaan

3. Diagram sekuen untuk use case lihat tentang

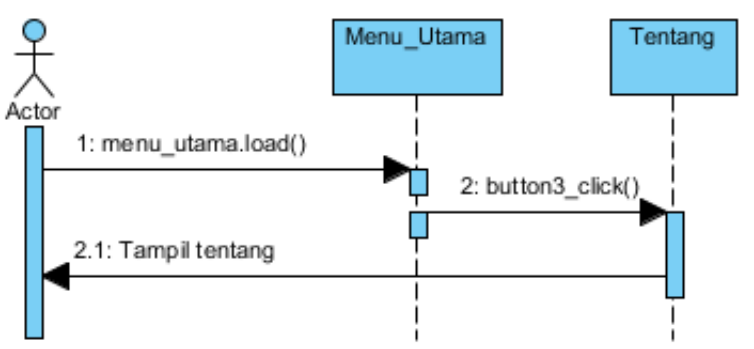

Gambar 4.Diagram sekuen lihat tentang

\subsubsection{Class Diagram}

Diagram Kelas menggambarkan sistem secara statis. Kelas diagram digunakan untuk menampilkan kelas-kelas dan paket-paket yang ada di dalam sistem serta menampilkan relasi antar kelas-kelas tersebut.

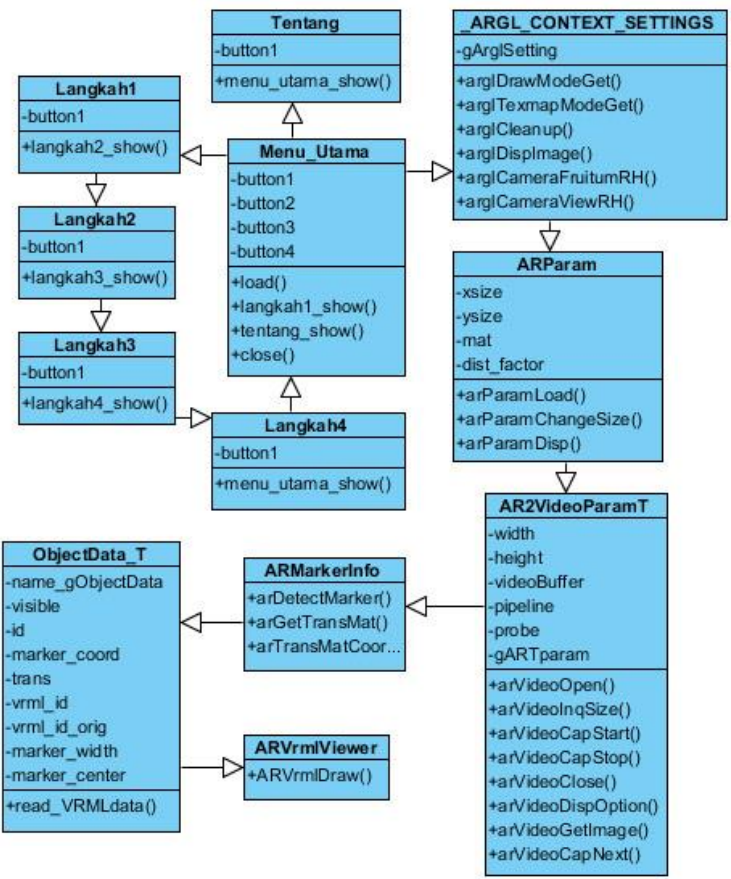

Gambar 8.Diagram kelas perancangan aplikasi 
3.3 Perancangan Antarmuka

3.3.1 Perancangan Tampilan Antarmuka Pengguna Perancangan tampilan antarmuka pengguna berfungsi untuk memberikan kemudahan kepada pengguna dalam menggunakan aplikasi. Tampilan antarmuka diawali dengan tampilan menu utama yang memiliki empat fungsi tombol yaitu:

1. Tombol "Mulai", yang berfungsi untuk menuju menu pilihan tampilan objek virtual 3D perumahan.

2. Tombol "Cara Penggunaan", yang berfungsi untuk menampilkan informasi mengenai bagaimana menggunakan aplikasi.

3. Tombol "Tentang", yang berfungsi untuk menampilkan informasi pembuat aplikasi.

4. Tombol "Keluar", yang berfungsi untuk keluar dari aplikasi.

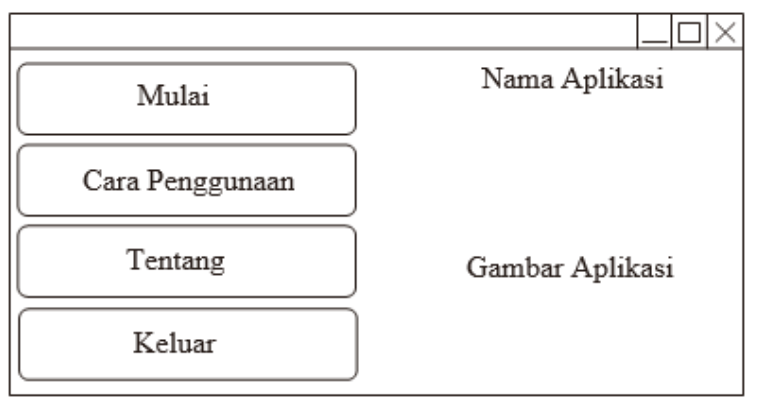

Gambar 9.Rancangan tampilan menu utama

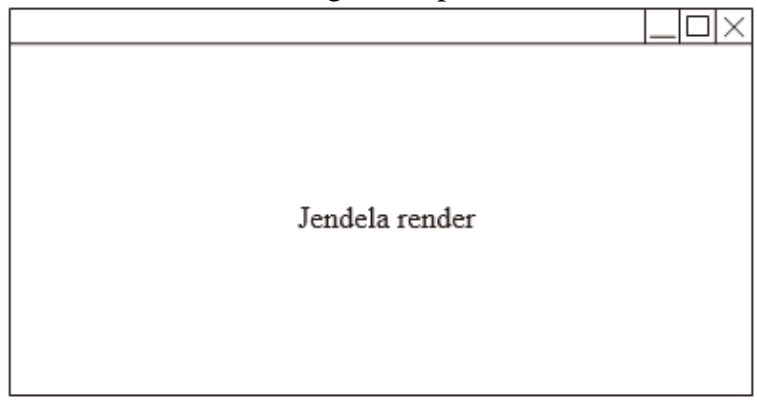

Gambar 10.Rancangan tampilan jendela render

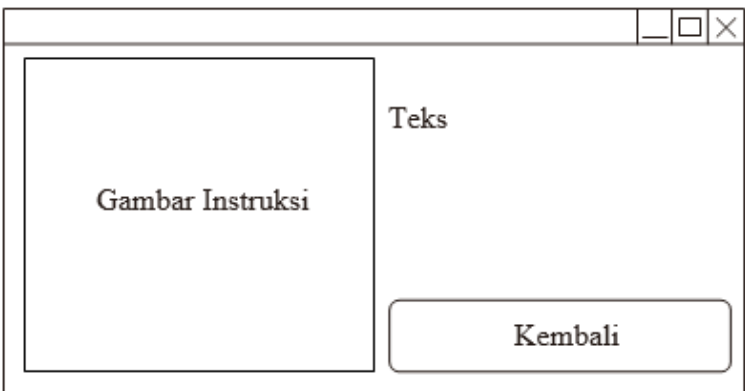

Gambar 11.Rancangan tampilan halaman menu "Cara Penggunaan"

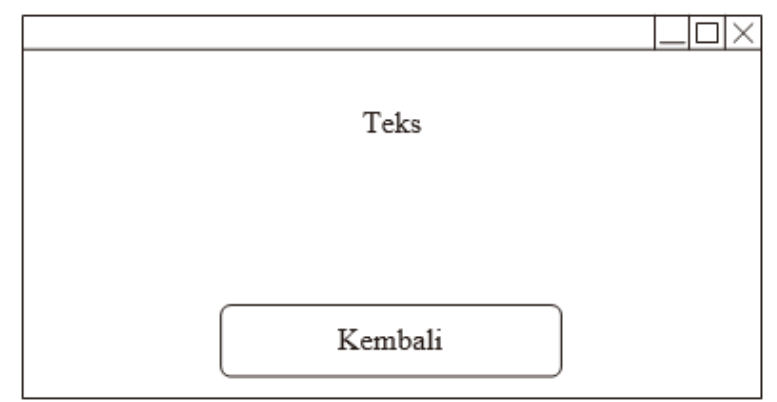

Gambar 12.Rancangan tampilan halaman menu "Cara Penggunaan"

\subsubsection{Perancangan Brosur Fisik}

Brosur fisik digunakan pengguna untuk berinteraksi terhadap aplikasi. Pada tampilan brosur fisik terdapat marker yang akan dikenali oleh aplikasi untuk menampilkan objek virtual 3D perumahan pada layar monitor.

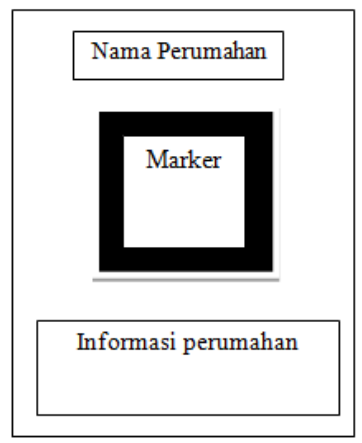

Gambar 13.Rancangan brosur fisik

\section{IMPLEMENTASI DAN PENGUJIAN SISTEM}

\subsection{Implementasi Sistem}

4.1.1 Implementasi Perangkat Keras dan Perangkat Lunak

Kebutuhan perangkat lunak yang digunakan dalam pembuatan augmented realityuntuk media promosi penjualan perumahan adalah sebagai berikut:

1. Microsoft Windows 7

2. ARToolkit Software Library Versi 2.7.1

3. Autodesk 3D Studio Max 2010

4. Adobe Photoshop CS5

5. CorelDRAW X5

6. Visual C++ 2008

7. Visual Studio 2010

8. Lux Meter

Kebutuhan perangkat keras yang digunakan dalam membangun augmented realityuntuk media promosi penjualan perumahan adalah sebagai berikut:

1. PC dengan kecepatan prosesor3,30 GHz

2. Random Access Memory (RAM) 4 GB

3. Harddisk dengan space $500 \mathrm{~GB}$

4. VGA 512 MB 128 Bits

5. Webcam

6. Printer

7. Penanda (marker)

8. Alat ukur (pengaris, busur) 
9. Smartphone dengan sensor cahaya

\subsubsection{Implementasi Program}

1. Implementasi Visualisasi 3D

Dalam membuat model perumahan visual 3 Dimensi menggunakan perangkat lunak 3Ds Max 2010.Tahap Implementasi Visualisasi 3D dilakukan dengan beberapa tahap yaitu tahap modeling, tahap texturing dan tahap exporting.

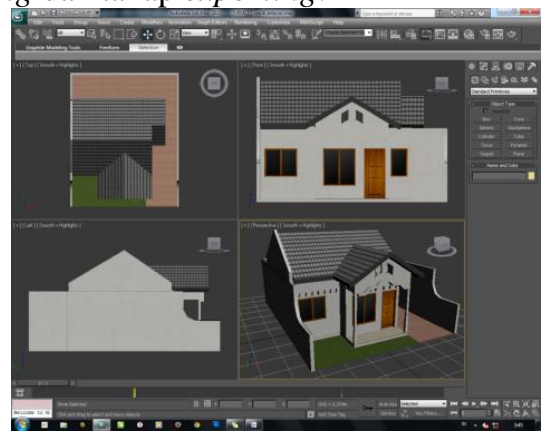

Gambar 14.Model rumah setelah diberi tekstur

2. Implementasi Pembuatan Penanda (Marker)

Pembuatan penanda (marker) menggunakan perangkat lunak Adobe Photoshop CS5.Untuk desain dasar penanda dapat memanfaatkan desain Blankpatt yang telah tersedia pada folder patterns di Library ARToolkit, selanjutnya memberi desain tambahan sebagai penanda (marker) dengan menggunakan Adobe Photoshop CS5.

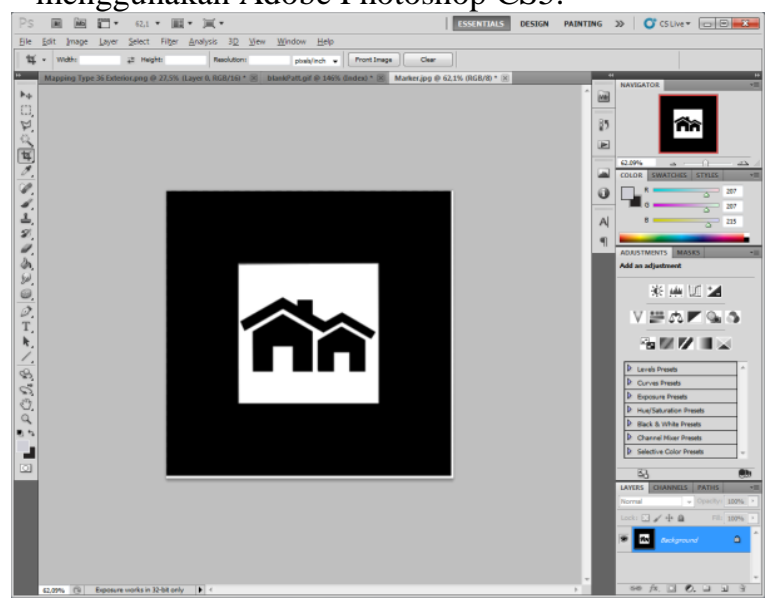

Gambar 15.Desain Penanda (Marker) Pada Adobe Photoshop CS5

Untuk dapat mendeteksi penanda, maka perlu dilakukan pengenalan penanda terlebih dahulu yaitu untuk mendapatkan pola dan sudut koordinat yang tepat. Mempolakan penanda dapat menggunakan tool Mk_patt.exe yang ada pada Library ARToolkit.

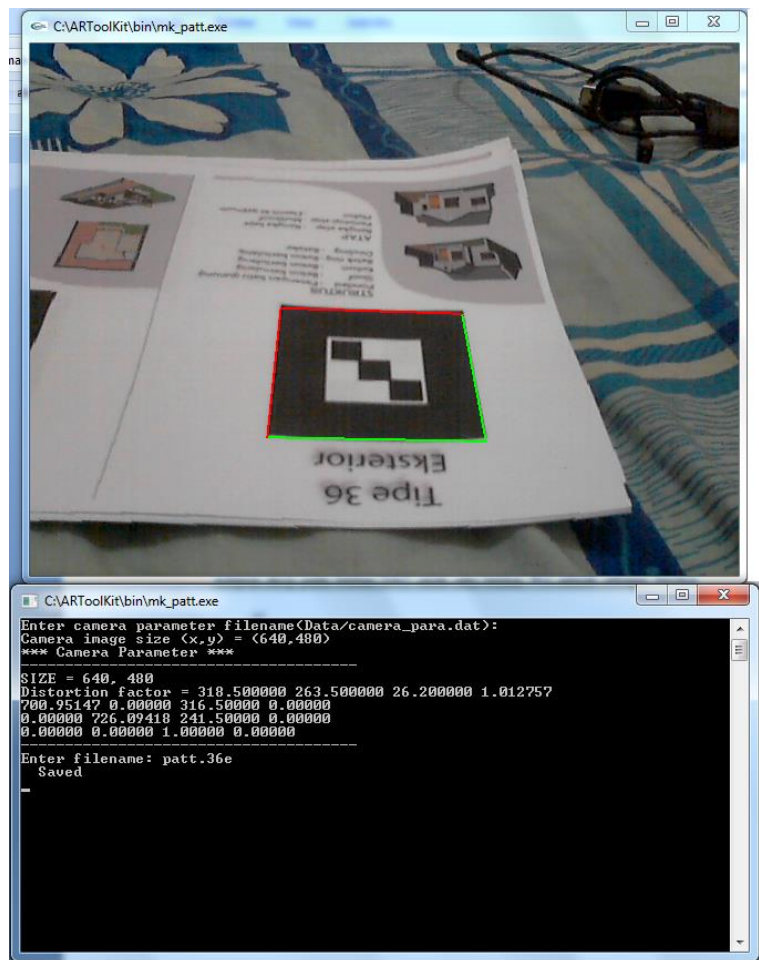

Gambar 16.Pengenalan marker baru menggunakan Mk_patt.exe

3. Implementasi Library ARToolkit

Setelah pada tahap implementasi visualisasi 3 dimensi menyisipkan berkas ekstensi .Wrl selanjutnya menambahkan berkas DAT untuk setiap berkas Wrl. Dimana berkas DAT berfungsi untuk menentukan posisi, arah, dan ukuran dari model 3 dimensi yang telah dibuat pada saat ditampilkan di atas penanda (marker).Adapun skrip pada berkas DAT salah satu berkas Wrl adalah sebagai berikut.

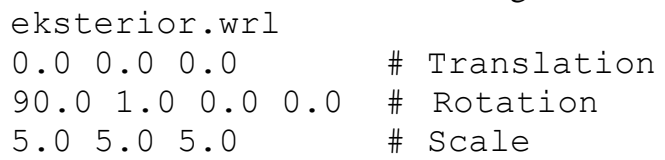
ARToolkit, dilakukan kompilasi (compiling) simpleVRML untuk mempaketkan library ARToolkit menjadi berkasexecutable. Kompilasi ini menggunakan Visual $\mathrm{C}++2008$ dengan melakukan konfigurasi pada $\mathrm{C} / \mathrm{C}++$ dan Linker di Properties project SimpleVRML. Setelah itu dilakukan Build (F7) dilanjutkan Debugproject (F5).

4. Implementasi Antarmuka

a. Implementasi Antarmuka Pengguna

Tampilan formulir menu utama terdiri dari 4 tombol navigasi. 4 tombol tersebut adalah tombol Mulai, tombol CaraPenggunaan, tombol Tentang, dan tombol Keluar. 


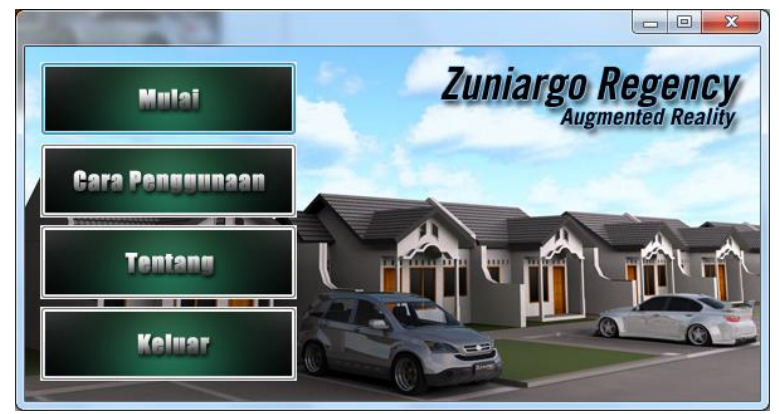

Gambar 17.Tampilan menu utama

b. Implementasi Antarmuka Brosur Fisik

Implementasi antarmuka brosur fisik dilakukan dengan mebuat desain brosur menggunakan perangkat lunak Adobe Photoshop CS5.

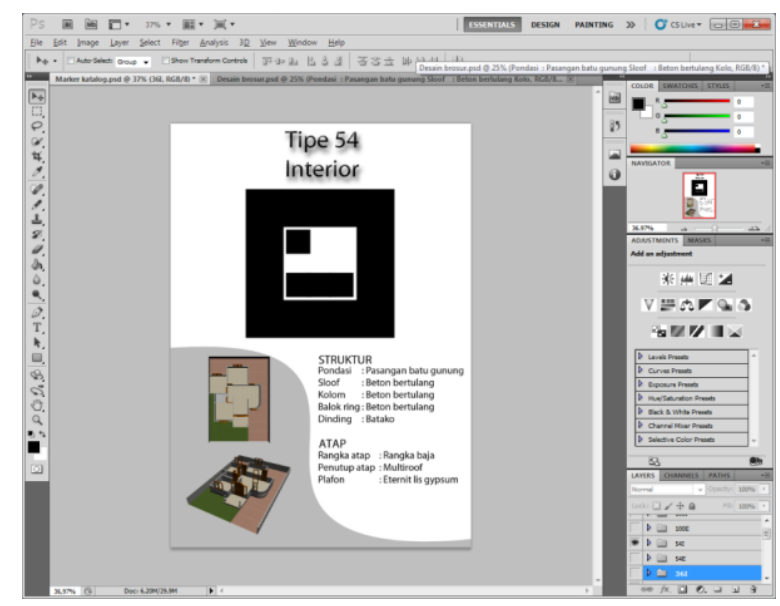

Gambar 18.Pembuatan desain brosur fisik

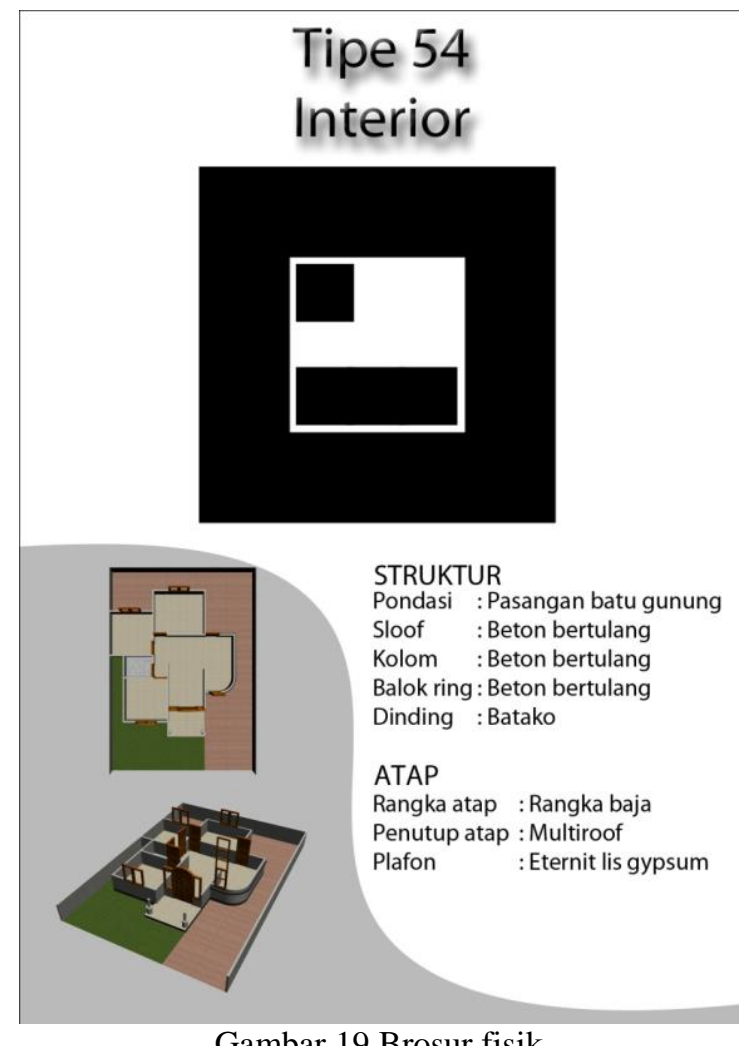

Gambar 19.Brosur fisik

\subsubsection{Pengujian Aplikasi}

Pengujian merupakan proses eksekusi suatu program dengan maksud untuk mengevaluasi sistem apakah telah berjalan sesuai dengan yang diinginkan. Pengujian sistem dilakukan dengan metode kotak hitam (black-box), dimana pengujian ini menekankan pada pengujian fungsionalitas dari aplikasi augmented reality sebagai media promosi penjualan perumahan ini.

Pengujian fungsionalitas pada aplikasi ini meliputi pengujian sudut kamera terhadap penanda (marker), pengujian jarak penanda (marker) ke kamera, pengujian cahaya serta pengujian tombol yang terdapat pada antarmuka aplikasi augmented reality sebagai media promosi penjualan perumahan ini.

1. Intensitas Cahaya, Pengujian Sudut Kamera, dan Jarak Kamera Terhadap Penanda (Marker)

Tabel 1.Pengujian intensitas cahaya, sudut kamera, dan jarak antara kamera dengan penanda (marker)

\begin{tabular}{|c|c|c|c|}
\hline $\begin{array}{c}\text { Intensitas } \\
\text { Cahaya }\end{array}$ & $\begin{array}{c}\text { Sudut } \\
\text { Kamera }\end{array}$ & $\begin{array}{c}\text { Jarak } \\
\text { Kamera }\end{array}$ & Hasil \\
\hline \multirow{12}{*}{$\begin{array}{c}1 \mathrm{~lx}-9 \\
1 \mathrm{x}\end{array}$} & \multirow{3}{*}{$30^{\circ}$} & $30 \mathrm{~cm}$ & Marker gagal terdeteksi \\
\hline & & $60 \mathrm{~cm}$ & Marker gagal terdeteksi \\
\hline & & $90 \mathrm{~cm}$ & Marker gagal terdeteksi \\
\hline & \multirow{3}{*}{$45^{\circ}$} & $30 \mathrm{~cm}$ & Marker gagal terdeteksi \\
\hline & & $60 \mathrm{~cm}$ & Marker gagal terdeteksi \\
\hline & & $90 \mathrm{~cm}$ & Marker gagal terdeteksi \\
\hline & \multirow{3}{*}{$60^{\circ}$} & $30 \mathrm{~cm}$ & Marker gagal terdeteksi \\
\hline & & $60 \mathrm{~cm}$ & Marker gagal terdeteksi \\
\hline & & $90 \mathrm{~cm}$ & Marker gagal terdeteksi \\
\hline & \multirow{3}{*}{$90^{\circ}$} & $30 \mathrm{~cm}$ & Marker gagal terdeteksi \\
\hline & & $60 \mathrm{~cm}$ & Marker gagal terdeteksi \\
\hline & & $90 \mathrm{~cm}$ & Marker gagal terdeteksi \\
\hline \multirow{12}{*}{$\begin{array}{c}18 \mathrm{~lx}- \\
30 \mathrm{~lx}\end{array}$} & \multirow{3}{*}{$30^{\circ}$} & $30 \mathrm{~cm}$ & Marker berhasil terdeteksi \\
\hline & & $60 \mathrm{~cm}$ & Marker berhasil terdeteksi \\
\hline & & $90 \mathrm{~cm}$ & Marker berhasil terdeteksi \\
\hline & \multirow{3}{*}{$45^{\circ}$} & $30 \mathrm{~cm}$ & Marker berhasil terdeteksi \\
\hline & & $60 \mathrm{~cm}$ & Marker berhasil terdeteksi \\
\hline & & $90 \mathrm{~cm}$ & Marker berhasil terdeteksi \\
\hline & \multirow{3}{*}{$60^{\circ}$} & $30 \mathrm{~cm}$ & Marker berhasil terdeteksi \\
\hline & & $60 \mathrm{~cm}$ & Marker berhasil terdeteksi \\
\hline & & $90 \mathrm{~cm}$ & Marker berhasil terdeteksi \\
\hline & \multirow{3}{*}{$90^{\circ}$} & $30 \mathrm{~cm}$ & Marker berhasil terdeteksi \\
\hline & & $60 \mathrm{~cm}$ & Marker berhasil terdeteksi \\
\hline & & $90 \mathrm{~cm}$ & Marker berhasil terdeteksi \\
\hline \multirow{12}{*}{$\begin{array}{l}901 x- \\
1401 x\end{array}$} & \multirow{3}{*}{$30^{\circ}$} & $30 \mathrm{~cm}$ & Marker berhasil terdeteksi \\
\hline & & $60 \mathrm{~cm}$ & Marker berhasil terdeteksi \\
\hline & & $90 \mathrm{~cm}$ & Marker berhasil terdeteksi \\
\hline & \multirow{3}{*}{$45^{\circ}$} & $30 \mathrm{~cm}$ & Marker berhasil terdeteksi \\
\hline & & $60 \mathrm{~cm}$ & Marker berhasil terdeteksi \\
\hline & & $90 \mathrm{~cm}$ & Marker berhasil terdeteksi \\
\hline & \multirow{3}{*}{$60^{\circ}$} & $30 \mathrm{~cm}$ & Marker berhasil terdeteksi \\
\hline & & $60 \mathrm{~cm}$ & Marker berhasil terdeteksi \\
\hline & & $90 \mathrm{~cm}$ & Marker berhasil terdeteksi \\
\hline & \multirow{3}{*}{$90^{\circ}$} & $30 \mathrm{~cm}$ & Marker berhasil terdeteksi \\
\hline & & $60 \mathrm{~cm}$ & Marker berhasil terdeteksi \\
\hline & & $90 \mathrm{~cm}$ & Marker berhasil terdeteksi \\
\hline \multirow{2}{*}{$\begin{array}{l}180 \mathrm{~lx}- \\
200 \mathrm{~lx}\end{array}$} & \multirow{2}{*}{$30^{\circ}$} & $30 \mathrm{~cm}$ & Marker berhasil terdeteksi \\
\hline & & $60 \mathrm{~cm}$ & Marker berhasil terdeteksi \\
\hline
\end{tabular}




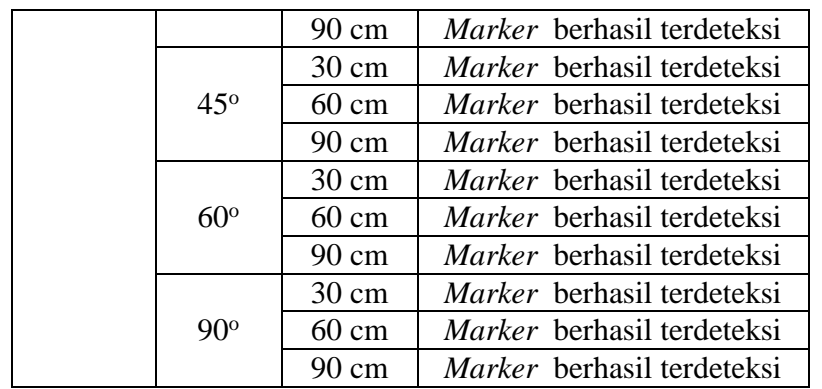

2. Pengujian Objek 3 Dimensi

Pengujian objek 3 dimensi bertujuan untuk menguji apakah objek-objek yang telah dibuat dapat ditampilkan sesuai dengan yang diharapkan.

a. Pengujian objek eksterior rumah tipe 36

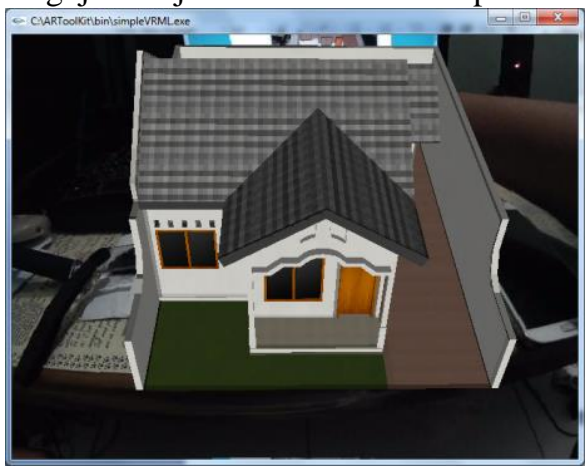

Gambar 20 Pengujian objek eksterior rumah tipe 36

b. Pengujian objek interior rumah tipe 36

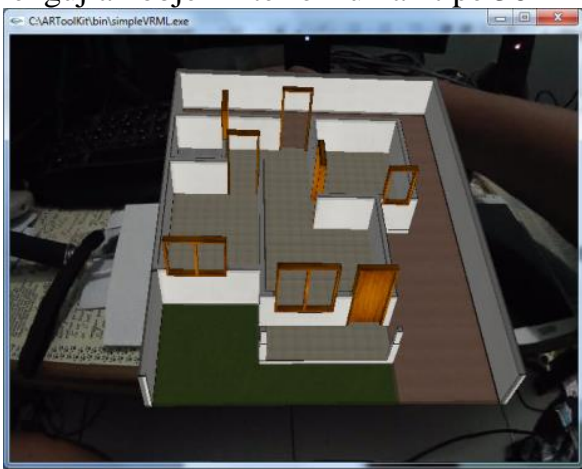

Gambar 21 Pengujian objek interior rumah tipe 36

c. Pengujian objek eksterior rumah tipe 54

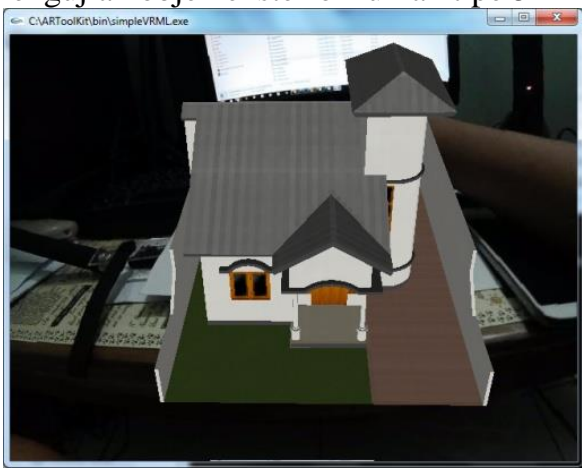

Gambar 22 Pengujian objek eksterior rumah tipe 54 d. Pengujian objek interior rumah tipe 54

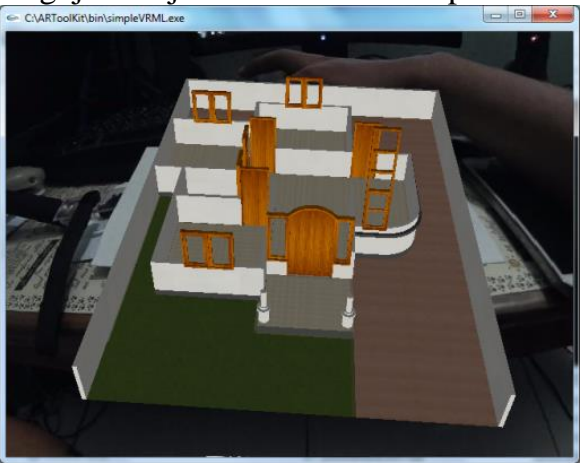

Gambar 23 Pengujian objek interior rumah tipe 54

e. Pengujian objek eksterior rumah tipe 100

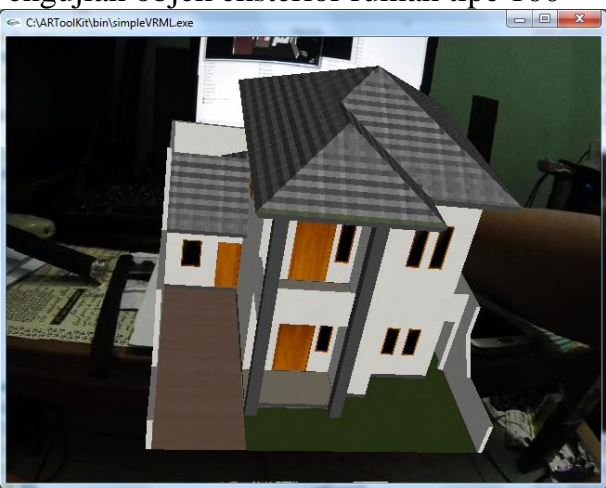

Gambar 24 Pengujian objek eksterior rumah tipe 100

f. Pengujian objek interior rumah tipe 100

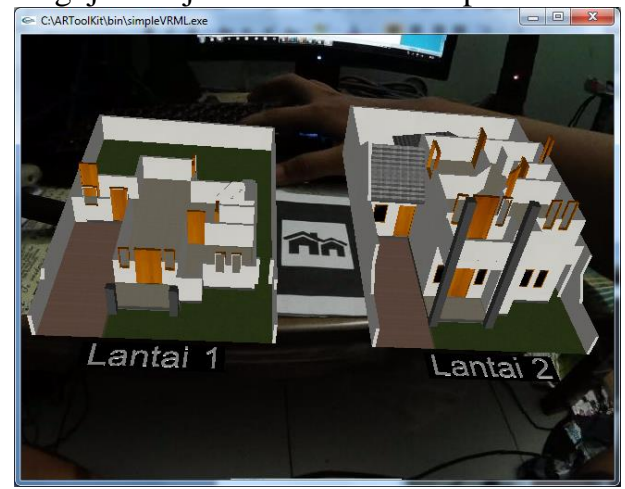

Gambar 25 Pengujian objek interior rumah tipe 100

g. Pengujian objek cluser

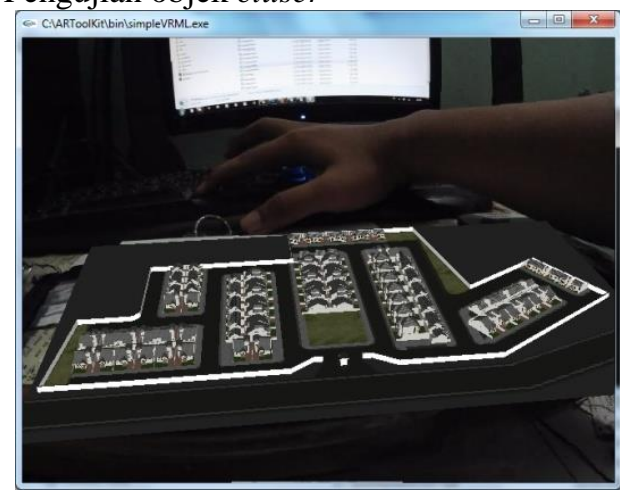

Gambar 26 Pengujian objek cluster 
3. Pengujian Tombol Antarmuka

Pengujian tombol antarmuka berfungsi untuk menguji apakah tombol-tombol navigasi telah bekerja sesuai yang diinginkan. Tabel4.2 menunjukkan hasil pengujian tombol antarmuka dalam aplikasi augmented reality sebagai media promosi penjualan perumahan.

Tabel 2.Pengujian tombol antarmuka

\begin{tabular}{|c|c|c|c|c|}
\hline No & Form & $\begin{array}{c}\text { Tombol } \\
\text { yang Diuji }\end{array}$ & Keterangan & Hasil \\
\hline \multirow{4}{*}{1} & \multirow{4}{*}{$\begin{array}{l}\text { Menu } \\
\text { utama }\end{array}$} & Mulai & $\begin{array}{c}\text { Ketika tombol } \\
\text { ditekan, maka } \\
\text { aplikasi akan } \\
\text { menuju form } \\
\text { menu pilihan } \\
\text { render }\end{array}$ & Benar \\
\hline & & $\begin{array}{c}\text { Cara } \\
\text { Penggunaan }\end{array}$ & $\begin{array}{c}\text { Ketika tombol } \\
\text { ditekan, maka } \\
\text { aplikasi akan } \\
\text { menampilkan } \\
\text { halaman } \\
\text { petunjuk } \\
\text { penggunaan } \\
\text { aplikasi. }\end{array}$ & Benar \\
\hline & & Tentang & $\begin{array}{c}\text { Ketika tombol } \\
\text { ditekan, maka } \\
\text { aplikasi akan } \\
\text { mengarah ke } \\
\text { halaman } \\
\text { informasi } \\
\text { aplikasi. }\end{array}$ & Benar \\
\hline & & Keluar & $\begin{array}{l}\text { Ketika tombol } \\
\text { ditekan, maka } \\
\text { aplikasi akan } \\
\text { keluar dari } \\
\text { aplikasi. }\end{array}$ & Benar \\
\hline \multirow{4}{*}{2} & \multirow{4}{*}{$\begin{array}{l}\text { Menu } \\
\text { pilihan } \\
\text { render }\end{array}$} & Cluster & $\begin{array}{c}\text { Ketika tombol } \\
\text { ditekan, maka } \\
\text { aplikasi akan } \\
\text { menampilkan } \\
\text { jendela render } \\
\text { cluster }\end{array}$ & Benar \\
\hline & & Eksterior & $\begin{array}{c}\text { Ketika tombol } \\
\text { ditekan, maka } \\
\text { aplikasi akan } \\
\text { menampilkan } \\
\text { jendela render } \\
\text { eksterior }\end{array}$ & Benar \\
\hline & & Interior & $\begin{array}{c}\text { Ketika tombol } \\
\text { ditekan, maka } \\
\text { aplikasi akan } \\
\text { menampilkan } \\
\text { jendela render } \\
\text { interior }\end{array}$ & Benar \\
\hline & & Kembali & $\begin{array}{c}\text { Ketika tombol } \\
\text { ditekan, maka } \\
\text { aplikasi akan } \\
\text { menuju form } \\
\text { menu utama }\end{array}$ & Benar \\
\hline 3 & Cara & Berikutnya & Ketika tombol & Benar \\
\hline
\end{tabular}

\begin{tabular}{|c|c|c|c|c|}
\hline & \multirow[t]{2}{*}{$\begin{array}{c}\text { Penggu } \\
\text { naan }\end{array}$} & & $\begin{array}{c}\text { ditekan, maka } \\
\text { aplikasi akan } \\
\text { menampilkan } \\
\text { ilustrasi } \\
\text { langkah } \\
\text { petunjuk } \\
\text { penggunaan } \\
\text { selanjutnya } \\
\end{array}$ & \\
\hline & & Kembali & $\begin{array}{c}\text { Ketika tombol } \\
\text { ditekan, maka } \\
\text { aplikasi akan } \\
\text { menuju form } \\
\text { menu utama }\end{array}$ & Benar \\
\hline 4 & Tentang & Kembali & $\begin{array}{c}\text { Ketika tombol } \\
\text { ditekan, maka } \\
\text { aplikasi akan } \\
\text { menuju form } \\
\text { menu utama }\end{array}$ & Benar \\
\hline
\end{tabular}

4. Analisa dan Pembahasan

Berdasarkan hasil pengujian aplikasi menggunakan metode black-box, pengujian sudut kamera, jarak kamera, dan intensitas cahaya terhadap penanda (marker), maka Tabel berikut menunjukkan prosentase keberhasilan pengujian intensitas cahaya, sudut kamera,dan jarak kameraterhadap penanda.

Tabel 3.Analisan dan pembahasan pengujian

\begin{tabular}{|c|c|c|c|c|}
\hline \multirow{2}{*}{$\begin{array}{c}\text { Intensitas } \\
\text { Cahaya }\end{array}$} & \multicolumn{2}{|c|}{ Pengujian } & \multirow{2}{*}{ Prosentase } & $\begin{array}{c}\text { Hasil } \\
\text { Prosentase }\end{array}$ \\
\cline { 2 - 4 } & Berhasil & Gagal & & \\
\hline $11 \mathrm{l}-9 \mathrm{~lx}$ & 0 & 12 & $\frac{0}{12} \times 100 \%$ & $0 \%$ \\
\hline $\begin{array}{c}18 \mathrm{~lx}-30 \\
\mathrm{~lx}\end{array}$ & 12 & 0 & $\frac{12}{12} \times 100 \%$ & $100 \%$ \\
\hline $\begin{array}{c}90 \mathrm{~lx}- \\
140 \mathrm{~lx}\end{array}$ & 12 & 0 & $\frac{12}{12} \times 100 \%$ & $100 \%$ \\
\hline $\begin{array}{c}180 \mathrm{~lx}- \\
200 \mathrm{~lx}\end{array}$ & 12 & 0 & $\frac{12}{12} \times 100 \%$ & $100 \%$ \\
\hline
\end{tabular}

\section{KESIMPULAN DAN SARAN}

5.1. Kesimpulan 
Berdasarkan hasil pengujian dan analisis aplikasi augmented reality sebagai media promosi penjualan perumahan, maka dapat disimpulkan beberapa hal sebagai berikut.

1. Teknologi augmented reality dapat diimplementasikan sebagaimedia promosi penjualan perumahan.

2. Teknologi VRML dapat diimplementasikan dalam pembuatan objek 3 dimensiperumahan guna mendukung aplikasi augmented reality sebagai media promosi penjualan perumahan.

3. Berdasarkan hasil pengujian dengan menggunakan metode black-box, intensitas cahaya mempengaruhi aplikasi augmented reality sebagai media promosi penjualan perumahan dalam mendeteksi atau mengenali penanda (marker).

4. Besar intensitas cahaya 18 lx- 30 lx, 90 lx - 140 lx, dan 180 lx - 200 lx dengan pengaturan sudut kamera $30^{\circ}-90^{\circ}$ serta jarak penanda (marker) ke kamera sejauh $30 \mathrm{~cm}-90 \mathrm{~cm}$ adalah komposisi yang baik agar aplikasi dapat menampilkan objek 3 dimensi.

5. Berdasarkan hasil pengujian menggunakan metode Black Box, tombol-tombol yang tersedia pada aplikasi augmented reality sebagai media promosi penjualan perumahan berfungsi dengan baik sesuai dengan fungsionalitasnya masingmasing.

\subsection{Saran}

Berdasarkan hasil pengujian dan analisis aplikasi augmented reality sebagai media promosi penjualan perumahan, dapat diberikan beberapa saran sebagai berikut.

1. Pengembang aplikasi augmented reality dapat melakukan pengembangan terhadap pembuatan objek 3 dimensiperumahan agar lebih menyerupai objek sesungguhnya namun dengan ukuran file yang kecil sehingga ukuran aplikasi tidak menjadi besar.

2. Pengembang disarankan dapat mengembangkan aplikasi augmented reality sebagai media promosi penjualan perumahan ini agar saat menampilkan objek 3 dimensi, aplikasi dapat menhasilkan bayangan dari objek 3 dimensi.

3. Pengembang disarankan dapat mengembangkan aplikasi augmented reality sebagai media promosi penjualan perumahan ini agar dapat dijalankan pada perangkat bergerak (mobile device) seperti smartphone.

\section{DAFTAR PUSTAKA}

[1] Anwar, B., 1999a. Belajar Sendiri Bahasa Pemrograman VRML 1.0, Jakarta: PT Elex Media Komputindo..
[2] Anwar, B., 1999b. Belajar Sendiri Bahasa Permrograman VRML 97, Jakarta: PT Elex Media.

[3] Ardiansyah, M., 2006. Perancangan Augmented Reality of Residential Area Design yang Didukung Computer Supported Cooperative Work untuk Developer.

[4] Azuma, R., 1997. A Survey of Augmented Reality. Presence: Teleoperators and Virtual Environments

[5] Coltekin, A., Heikkinen, J. \& Ronnholm, P., 2003. Studying Geometry, Color, and Texture in VRML, Helsinki: Institute of Photogrammetry and Remote Sensing, Helsinki University of Technology.

[6] Fadillah, M.H., 2011. Implementasi VRML pada Media Pembelajaran Geometri untuk Sekolah Dasar dengan Menggunakan Metode Pembentukan Objek Ekstrusi. Institut Pertanian Bogor.

[7] Jiwatama, A.R., 2012. Implementasi Augmented Reality sebagai Media Promosi Trans Studio Bandung dengan Menggunakan ARToolkit.

[8] Kaufmann, H., 2002. Construct3D: An Augmented Reality for Mathematics and Geometry: ACM Press.

[9] Kurniadi, A., 1999. Membuat Dunia 3D dengan VRML, Jakarta: PT Elex Media Komputindo.

[10] Lethbridge, T., \& Laganiere, R., 2002. ObjectOriented Software Engineering: Practical Software Development using UML and Java: McGraw-Hill Irwin.

[11] Siahaan, R.F., 2014. Implementasi Sistem Informasi Geografis Daerah Pariwisata Kota Semarang Berbasis Android dengan Global Positioning System (GPS).

[12] Soma, H.A., 2007. Dasar-Dasar Modeling dan Animasi Dengan 3D Studio Max, Jakarta.

[13] Sommerville, 2003. Software Engineering, 6th ed. Jakarta: Erlangga.

[14] Whitten, J.L., Bentley, L.D., \& Dittman, K.C., 2004. System Analysisand Design Methods: McGraw-Hill Irwin. 